\title{
Covid-19. \\ La vigencia del higienismo decimonónico en tiempos de cuarentena
}

\section{Juan Santiago Palero}

Arquitecto. Doctor en Arquitectura. Docente de la FAUD, UNC en dos cátedras de Historia de la Arquitectura. Becario posdoctoral de CONICET trabajando en el INVIHAB FAUD UNC. Director de un proyecto de investigación SeCyT de la Universidad Nacional de Córdoba. Integrante de un equipo de investigación con financiación SIIP de la UNCuyo.

juansantiagoarqpalero@gmail.com

\section{Mariel Avila}

Arquitecta. Maestranda de la Maestría en Gestión y Desarrollo Habitacional de FAUD, UNC. Becaria SeCyT de la UNC trabajando en el INVIHAB FAUD UNC.

arqmarielavila@gmail.com

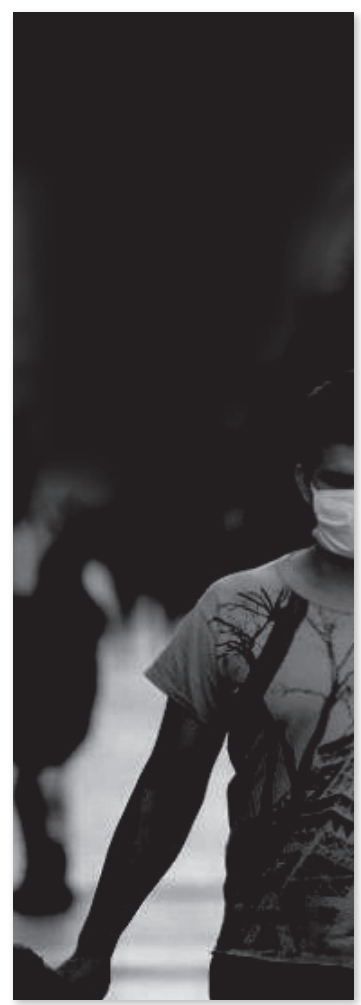

http://dx.doi.org/10.30972/crn.29294620

ISNN 1666-6186. Volumen 29 N. ${ }^{\circ} 29$ (Diciembre de 2020) Pp. 009-026 - Recibido: 27-02-20. Evaluado y aprobado: 14-05-20 
Covid-19. La vigencia del higienismo decimonónico en tiempos de cuarentena

\section{Resumen}

Ante la crisis global desatada por la Covid-19, este trabajo aporta reflexiones desde la Arquitectura y el Urbanismo. Las disciplinas proyectuales siguen una extraña paradoja. Por un lado, plantean soluciones para el futuro; por otro lado, aprenden desde la experiencia, revisando el pasado. En este contexto se propone revisar la incidencia de otras crisis sanitarias sobre la vida urbana. En particular, este artículo focaliza sobre la cosmovisión higienista, que sentó las bases del proceso de modernización de la ciudad y la vivienda a fines del siglo XIX. El articulo recoge tres aspectos: el control social, el recambio tecnológico y la intervención en las condiciones habitacionales, realizando un contrapunto entre pasado y presente para analizar cómo estas facetas recobran vigencia ante el coronavirus.

\section{Palabras clave}

Higienismo; Covid-19; arquitectura; urbanismo.

\section{Covid-19. The validity of decimononic hygienism in times of quarantine}

\author{
Covid-19. A validade do \\ higienismo decimonônico em \\ tempos da quarentena
}

\begin{abstract}
Faced with the global crisis unleashed by Covid-19, this work provides reflections from the point of view of Architecture and Urbanism. The design disciplines follow a strange paradox. On the one hand, they propose solutions for the future; on the other hand, they learn from experience, reviewing the past. In this context, it is proposed to review the incidence of other health crises on urban life. In particular, this article focuses on the hygienist worldview, which laid the foundations for the modernization process of the cities and housing at the end of the 19th century. The paper includes three aspects: social control, technological change and intervention in housing conditions, making a counterpoint between past and present to analyze how these facets regain validity arose again with the crisis of coronavirus.
\end{abstract}

\section{Key words}

Hygienism; Covid-19; architecture; urban planning.

\section{Resumo}

Diante da crise global desencadeada pela Covid-19, esta obra traz reflexões a partir da Arquitetura e do Urbanismo. As disciplinas de design seguem um estranho paradoxo. Por um lado, eles propõem soluções para o futuro; por outro lado, aprendem com a experiência, revisando o passado. Nesse contexto, propõe-se revisar a incidência de outras crises sanitárias na vida urbana. Em particular, este artigo enfoca a visão de mundo higienista, que lançou as bases para o processo de modernização da cidade e da habitação no final do século XIX. O artigo contempla três aspectos: controle social, mudança tecnológica e intervenção nas condições de moradia, fazendo um contraponto entre o passado e o presente para analisar como essas facetas ganham validade diante do coronavírus.

Palavras chave

Higienismo; Covid-19; arquitetura; urbanismo. 


\section{Recuerdos del higienismo}

La incorporación de las tecnologías surgidas en la Revolución Industrial sumada a la consolidación del liberalismo económico y el afianzamiento del colonialismo generaron un proceso de crecimiento caótico de las ciudades. Las expresiones artísticas del realismo describían la profunda desigualdad de las metrópolis europeas, contrastes que se mantenían en aquellas ciudades transformadas en nodos extractivos de los imperios coloniales ${ }^{1}$.

Peter Hall describe las condiciones habitacionales de la población trabajadora de aquella época bajo el título "la ciudad de la noche espantosa"2. Era una ciudad donde la explotación laboral, la especulación inmobiliaria y la nula preocupación estatal por las problemáticas de la población trabajadora se combinaban para generar intersticios urbanos o caseríos en la periferia caracterizados por el hacinamiento, la falta de infraestructuras básicas y la precariedad material. Estas condiciones deficitarias provocaban diferentes problemáticas urbanas, desde frecuentes inundaciones, incendios, conflictos sociales y, por supuesto, la rápida propagación de enfermedades.

En ese contexto, el higienismo surgió como una corriente intelectual que recuperaba de la Ilustración la confianza en las ciencias - principalmente en la medicina - como fundamento para transformar las condiciones de vida de la población. Las ideas de Johannes Peter Frank ${ }^{3}$ marcaron un primer punto de auge con respecto a la intención de mejorar la salubridad en la ciudad. A finales del siglo XIX, los aportes de Luis Pasteur brindaron un nuevo impulso a las ideas higienistas, poniendo énfasis en la "higiene social"4.

En sus inicios, las transformaciones que impulsaron los higienistas abarcaron —entre otros ámbitos de acción - la modernización de la ciudad mediante la provisión de infraestructuras, la incorporación del verde y el tratamiento especial de ciertos equipamientos que consideraban dañinos para la salubridad de la población, como cementerios, hospitales e industrias. A fines del siglo XIX y principios del siglo XX, las ideas del higienismo se combinaron
1. Entre 1800 y 1890 la Revolución Industrial provocó un acelerado crecimiento demográfico en las principales ciudades europeas. "[Las] ciudades colapsaron sus estructuras: los viejos edificios escalaron en altura, [...] las parcelas $y$ viviendas se subdividieron y la densidad se hizo insoportable [...] en la periferia, donde el proletariado se hacinaba en lúgubres habitaciones mal iluminadas y peor ventiladas" (GARCÍA VÁZQUEZ, 2016, p. 14). En Argentina, a principios del siglo $\mathrm{XX}$, "los sectores sociales de bajos recursos quedaron librados a su suerte y limitados a su propia iniciativa, residiendo en inquilinatos o conventillos o en el peor de los casos alojados en cama caliente [...], o en los caños albergados en el puerto" (CRAVINO, 2016, p. 9).

2. El título corresponde al segundo capítulo del libro Ciudades del mañana (HALL, 1996, pp. 25-55).

3. En 1790, este médico alemán brindó una conferencia que marcó el rumbo del higienismo utilizando el título: "De populorum miseria: morborum genitrice”. Traducción propia: "la miseria del pueblo: madre de las enfermedades". Esta frase refleja un temor implícito en las primeras transformaciones urbanísticas: las condiciones deficitarias del hábitat, por agudizar los problemas de salud, ponen en riesgo a toda la población (MEDINA DE LA GARZA \& KosCHWITZ, 2011).

4. "Alrededor de 1890 en adelante, en donde se introducen los criterios pasteurianos, termina la creencia en 'miasmas pútridos' y se reformulan las prácticas y estrategias higiénicas. Se produce una nueva reformulación de las competencias, temas y problemas de la higiene poblacional, dando paso al nacimiento de la higiene social" (PAIVA, 1997, p. 5). 
5. En Europa "las huelgas de alquileres y la politización de las relaciones inquilino-casero en que desembocó el largo período de incubación de la crisis fueron rasgos de diversas grandes ciudades

[...] En Budapest, el conflicto estalló a partir de 1907; en Viena en 1911 [...] la gran huelga de Glasgow de 1915" (OYON BAÑALS, 2003, p. 13). "En Argentina la movilización que tuvo mayor impacto sobre las políticas posteriores y las actitudes de los sectores dominantes fue, sin duda, la de la 'protesta de alquileres' de 1907”' (YuJNOvsKY, 1974, p. 334).

6. En 1830 se da en Francia la epidemia de cólera, y en 1831, en Inglaterra (BENEVOLO, 1963). En Argentina la epidemia de fiebre amarilla fue en 1871 en Buenos Aires, con antecedentes en 1858, y cólera en 1867/1868 (CRAVINO, 2016).

7. Estas casas colectivas de inquilinato solían constar de un sistema de patios mínimos donde se disponían infraestructuras precarias de uso colectivo y habitaciones de alquiler para familias enteras o grupos de hombres. Los primeros conventillos utilizaban viejas casonas familiares, aunque la

rentabilidad que alcanzaron por el arribo de inmigrantes a principios del siglo XX posibilitó la construcción de nuevos edificios que seguían ese esquema tipológico (CRAvino, 2016).

8. Esta visión sesgada se aprecia en las palabras del médico cordobés Juan Cafferata: "El conventillo es una lacra. Allí habita la promiscuidad, germina la rebeldía, florece la tuberculosis, se disgrega la familia, se corrompe la niñez y naufraga la edad madura. Los conventillos son atroces. Las suciedades en contacto.

El pudor y la independencia imposibles. Las pasiones acechando pared de por medio en luch a y contacto cotidianos [...] Este es el conventillo, foco de todas ruindades" (CAFFERATA citado en CRAVINo, 2016, p. 15).

9. Este texto puede encontrarse en el libro Obras Escogidas (MARX \& ENGELS, 1975). con las expresiones políticas de reforma social para extender el radio de acción estatal con motivos de salud pública hacia el ámbito doméstico. Esta postura reflejaba una vinculación entre los problemas de salubridad y los hábitos de la población, cuestionando el comportamiento e, incluso, la moral de las personas. Esta intención de controlar a las clases populares se asentaba en una amenaza cierta. Los sucesivos levantamientos que atravesó el siglo XIX se apoyaron en un reclamo para mejorar las condiciones de vida de la población de menores ingresos 5 .

Frente a la rápida propagación de las epidemias ${ }^{6}$ del siglo XIX, las ideas higienistas ganaron protagonismo instalándose en el programa de gobierno de distintas facciones políticas. Estas ideas se encuentran en las bases conceptuales de las primeras intervenciones del urbanismo moderno, incluyendo algunos ejemplos tópicos, como el Paris de Haussmann (1851-1870), el ensanche de Cerdá en Barcelona (desde 1859) y la ciudad de La Plata (fundada en 1882) en Argentina, pero también transformaciones parciales de menor escala, como ramblas, parques, equipamientos sanitarios y barrios para población de menores ingresos.

En Argentina, los higienistas concentraron sus energías en la denuncia y erradicación de los conventillos ${ }^{7}$. En ciudades como Buenos Aires, los conventillos alcanzaron a alojar al $25 \%$ de la población en su momento más crítico (Cravino, 2016), coexistiendo con otras condiciones deficitarias del hábitat, como camas calientes, mazmorras en galpones y casillas o carpas en los rancheríos instalados en la periferia. Sin atender a las múltiples manifestaciones de la pobreza urbana, el higienismo veía en el conventillo la concentración de todos los males de la sociedad. Se consideraba que allí las condiciones deficitarias de infraestructura sanitaria, asoleamiento, ventilación y hacinamiento se combinaban con la vida licenciosa y revoltosa de las masas populares ${ }^{8}$.

Las ideas higienistas con respecto a la vivienda y la ciudad han sido ampliamente cuestionadas. Algunas de las críticas más agudas pueden rastrearse en Contribución al problema de la vivienda ${ }^{9}$ (1887). En este texto, EnGELs criticaba las primeras iniciativas filantrópicas y las 
intervenciones de corte haussmanniano por su carácter paternalista, por esconder las causas que generaban las condiciones deficitarias de la vivienda y por promover el control social de la población de menos ingresos.

En las ciudades latinoamericanas, las ideas higienistas se combinaron con la misericordia católica difundida por la encíclica Rerum Novarum (1891) para impulsar diferentes transformaciones urbanas. Estas iniciativas se caracterizaron por un fuerte control social, un recambio tecnológico que exaltaba la incorporación de infraestructuras modernas de saneamiento y la intención de intervenir desde asociaciones colectivas -e incluso desde los mecanismos del Estado- en el ámbito de la vivienda.

\section{El desafío actual}

Un nuevo brote del coronavirus en humanos comenzó a estudiarse en Wuhan, China, a fines de 2019, e inició su rápida expansión por el mundo en los primeros meses de $2020^{10}$. Por ser este un fenómeno cercano en el tiempo, resulta conveniente dejar paso a las investigaciones epidemiológicas para terminar de comprender la repentina expansión del virus. Desde el punto de vista urbano-territorial, la pandemia de la Covid-19 evidenció el nivel de interconexión e interdependencia de las ciudades dentro de una red de alcance global, reflejo de la distribución internacional de la producción y el consumo. La pandemia mostró una expansión más acelerada en aquellas ciudades o regiones mejor posicionadas en la competencia internacional por disputar los centros de mando de la producción, las finanzas y los flujos del turismo.

El llamado de alarma de la pandemia tardó en instalarse, tanto en la consciencia de la población como en las agendas de gobierno. Probablemente, el constante bombardeo mediático sensacionalista que caracteriza la híper-conectividad del siglo XXI contribuyó a generar un estado de incredulidad y desatención con respecto al tema. En otros casos, primó un profundo desinterés por las problemáticas de salud pública, cuyas consecuencias siempre repercutieron de manera más dramática en las clases históricamente postergadas ${ }^{11}$.

Una vez que las ciudades del mundo se transformaron en el escenario prioritario desde donde poder incidir en el control de la pandemia, los diferentes estamentos del Estado desplegaron una serie de medidas según sus condicionantes y posibilidades. En las diversas estrategias adoptadas se evidenciaron con todo dramatismo las desigualdades entre los
10. Silvia Ribeiro indica en una entrevista: "Lo que sí se conoce es que empieza a ser una infección significativa en una ciudad de China. Sin embargo, este no es el origen, sino el lugar en donde se manifiesta primero" (RIBEIRO, 2020).

\section{El filósofo alemán} Gabriel Markus señala: " $\mathrm{L} a$ pandemia nos lo enseña con los prejuicios racistas que se expresan por doquier. Trump intenta por todos los medios clasificar el virus como un problema chino; Boris Johnson piensa que los británicos pueden solucionar la situación por la vía del darwinismo social y provocar una inmunidad colectiva eugenésica" (MARKUS, 2020). 
12. En Argentina, Cravino aporta datos acerca del poder de inspección de la "Sociedad

Protectora del Obrero" y menciona también el art. 8 de la ley de Casas Baratas, que proponía el desalojo de

familias que provocaran

"escándalos o malos ejemplos" (CRAVINo, 2016). En Córdoba, Boixadós destaca el control social que estableció

la propuesta de vivienda obrera desarrollada por el catolicismo a principios de siglo XX (BoIXADós, 2012).

13. En este período se desarrolló una "mirada política" sobre los patios de los conventillos, como espacios donde se propagaban las ideas socialistas y anarquistas (CRAVINO, 2016). diferentes países del mundo en lo que respecta a la concepción de la salud pública, pero también en cuanto a las condiciones de vida en la ciudad.

A nivel urbano se desplegaron una serie de actuaciones que combinaban estrategias ya implementadas en otras contingencias anteriores, junto a las posibilidades tecnológicas derivadas de la informática y las comunicaciones (TIC). Dentro del amplio conjunto de medidas deben mencionarse las siguientes: la reorganización y ampliación del sistema sanitario a partir de nuevos equipamientos de salud, desde respiradores, máscaras, equipos que miden la temperatura, hasta la construcción de hospitales exprés; la incorporación de tecnologías para la detección, georreferenciación, seguimiento satelital y tratamiento de los infectados; la restricción del transporte y el espacio público; el aislamiento obligatorio domiciliario o comunitario (cuarentena) y la apuesta por el teletrabajo y la educación virtual para sobrellevar el aislamiento.

La multiplicidad de acciones programadas para enfrentar esta pandemia conduce a reflexionar con respecto a las amenazas y oportunidades que se avizoran desde la disciplina arquitectónica y urbana. Principalmente, al constatar que - ante la amenaza de la Covid-19- vuelven a surgir viejas prerrogativas del higienismo del siglo XIX.

\section{Un nuevo control social}

Las ideas del higienismo pusieron un énfasis especial en la transformación de las condiciones físicas del hábitat, procurando intervenir en el comportamiento de la población siguiendo preceptos de salud pública. El discurso higienista dejaba flotando en el imaginario colectivo que las costumbres de los sectores populares engendraban insalubridad, por lo cual, la ciencia debía educar a la población, sacarla de su ignorancia y modernizarla. Las iniciativas de construcción de vivienda para obreros por parte de entidades filantrópicas o estatales asociadas al higienismo exigieron el cumplimiento de rígidos códigos de comportamiento, que imponían, por ejemplo, ir a la iglesia, trabajar, no beber ${ }^{12}$, entre otros. Además, fue muy importante también el refuerzo de la idea de "núcleo familiar" como estrategia para desarticular la formación de colectivos políticamente activos, percibidos desde las elites como grupos conflictivos y revoltosos. Se consideraba que parte de los vicios morales de las clases populares eran resultado de los malos hábitos que se difundían en la vida comunitaria de los patios y galerías ${ }^{13}$ de los conventillos. Tanto la tipología arquitectónica como la normativa perseguían un mismo objetivo: enseñar a una población, que consideraban atrasada, a vivir en un mundo moderno. 
En medio de la pandemia, la Covid-19 ha despertado un latente espíritu de control social, normalización y vigilancia fundamentado en preceptos de salubridad. El señalamiento del otro (el vecino, el transeúnte) como infractor y posible amenaza para la salud colectiva revive una nueva versión del espíritu decimonónico que depositaba la culpabilidad en el individuo sin atender a factores socialmente determinados. La desigualdad en la distribución de las tareas de reproducción (compras, limpieza, cuidado de personas), la informalidad en el trabajo, el acceso desigual al transporte, equipamientos e infraestructuras no son tenidos en cuenta a la hora de señalar, juzgar e incluso coaccionar sobre el comportamiento de las personas.

En primer lugar, hay que aclarar que el establecimiento de normas de comportamiento social para prevenir la expansión del virus constituye, hoy, una estrategia efectiva y validada desde diferentes miradas científicas, razón por la cual estas medidas deben ser asumidas con toda responsabilidad. Sin embargo, es importante destacar que las nuevas normativas y la represión de las infracciones no logran su objetivo si no se complementan con campañas de información, construcción de consensos colectivos y, fundamentalmente, la indagación con respecto a las causas que dificultan su cumplimiento. Dentro de estas dificultades, las desigualdades urbanas constituyen un factor determinante. En la pandemia, la ciudad contemporánea, desigual y fragmentada, evidencia diferentes modalidades de control social según las características socio-ambientales de los distintos barrios y sectores de la ciudad.

La fragmentación urbana y la conformación de enclaves dentro del tejido condicionan una aplicación desigual de la normativa. Los enclaves físicos se traducen en enclaves de derecho, donde la discontinuidad física de la ciudad sirve de soporte a situaciones de excepción legal. Un ejemplo de ello es el decreto emitido por el intendente de Pilar para garantizar el cumplimiento de las medidas de aislamiento dentro de los barrios privados (countries) donde los vecinos no entendían que "tienen que hacer lo mismo que todos los habitantes"14. Como contraposición, en aquellos barrios populares, villas y asentamientos que no han sido formalmente integrados a la trama urbana se acentúa aún más la faceta represiva del Estado. Las fuerzas de seguridad, que suelen marcar una presencia amenazante para los vecinos de estos barrios, aprovecharon el respaldo social para desplegar diferentes formas de intimidación, e incluso castigos físicos sobre los infractores ${ }^{15}$.

La normativa no puede desentenderse de las características urbanas que posibilitan, dificultan o impiden su cumplimiento, dado que la población se encuentra en condiciones muy dispares para llevar a cabo algunas medidas, como por ejemplo el aislamiento ${ }^{16}$.
14. El intendente de Pilar anunció el decreto municipal $N .^{\circ} 6769 / 58$, debido a que en los countries "no se estaba cumpliendo el reglamento dictado por el Estado Nacional" (TN TODo NoticIAS, 2020).

\section{El Ministerio Público} de Defensa de la Ciudad Autónoma de Buenos Aires $(C A B A)$ realizó un informe entre el 20 y el 31 de marzo de 2020 donde se registraron trece denuncias por hechos de violencia institucional, incluyendo amenazas, malos tratos, falta de identificación policial, detenciones arbitrarias, golpes y utilización de gas pimienta (MINISTERIo PÚbLICO DE LA DEFENSA CABA, 2020).

16. El Registro Nacional de Barrios Populares (RENABAP) tiene anotados 4416 barrios populares donde habitan más de 4.000.000 de personas. En estos barrios, el $68 \%$ de los habitantes no accede formalmente al servicio de electricidad, el $89 \%$ no tiene agua corriente, el $98 \%$ no tiene cloacas y el $99 \%$ carece de gas natural (MINISTERIO DE DESARROLLO TERRITORIAL Y HÁBITAT, 2020). 
17. Aunque no pueden emitirse conclusiones aún, hay que rescatar que el Estado Nacional argentino ha comenzado a tener en cuenta estas dificultades. El Decreto de Necesidad de Urgencia 355/2020 publicado el 11 de abril, en su artículo 2, fija las condiciones para la aplicación de una cuarentena comunitaria en zonas específicas (BOLETÍN OFICIAL DE LA RepÚblica ARgeNTINA, 2020).

18. Traducción propia de la frase "the Law in all its Majesty has declared that neither rich man nor poor man has the right to sleep under bridges" (ANATOLE FRANCE Citado en BURGESS, 1978, p. 1125).
Las dificultades para cumplir la normativa se hacen más agudas en los barrios poco consolidados, donde la falta de infraestructuras, equipamientos y posibilidades laborales obliga a sus vecinos a moverse diariamente a otros sectores de la ciudad, donde paradójicamente son estigmatizados y racializados como intrusos ${ }^{17}$.

Insistir en la transformación de las condiciones de salud exclusivamente a través de la instauración de leyes combina ciertas dosis de ignorancia sobre las condicionantes socioeconómicas, obstinación y cinismo. Esta fe decimonónica en la normativa termina confundiendo las causas y los efectos. Las causas de gran parte de los problemas de salud comunitaria - no solo en épocas de pandemia - deben rastrearse en la dimensión habitacional de las desigualdades socioeconómicas; mientras que las restricciones normativas solo se limitan a reprimir sus efectos. Ya en el siglo XIX, Anatole France ironizaba con respecto al tema cuando decía: "La ley, con toda su majestuosidad, ha declarado que ni el rico ni el pobre tienen derecho a dormir debajo del puente"18.

Al control social ejercido desde las normativas se suma, durante el siglo XXI, la vigilancia digital, es decir, la multiplicidad de recursos tecnológicos que permiten controlar el comportamiento de la población a través de la informática y las telecomunicaciones. El reconocimiento facial en el espacio público, el seguimiento a través del uso de redes sociales, telefonía, transporte, transacciones bancarias y compras permiten realizar un auténtico espionaje sobre el comportamiento individualizado de las personas. El filósofo surcoreano ByunG-CHUL HAN advierte sobre el papel contradictorio que cumplieron estos recursos en el control de la Covid-19 en los países asiáticos. Por un lado, la vigilancia digital contribuyó a controlar la pandemia; por otro lado, la contingencia sirvió para aumentar y justificar el uso de estos mecanismos opresivos (HAN, 2020). Es por eso que Han recupera la Doctrina del Shock (2007), descrita por NAOMI KLEIN como aquella vieja estrategia que permite a los grupos de poder aprovechar los períodos de crisis y angustia colectiva como una oportunidad para implementar medidas opresivas que no se adoptarían bajo circunstancias normales (KLEIN, 2010).

Por el momento, los países latinoamericanos se encuentran lejos de lograr instalar la vigilancia digital en todos los ámbitos de la vida, principalmente por la dependencia tecnológica y la falta de infraestructuras de telecomunicaciones. Una parte importante de las actividades de la sociedad se desarrollan en ámbitos informales, lo cual dificulta la permeabilidad desde redes informáticas. Sin embargo, es 
probable que el imparable avance de estas tecnologías se acompañe también con una creciente vigilancia digital en todos los ámbitos de la vida.

Como rasgo esperanzador, hay que destacar aquellos casos en los cuales la cuarentena busca apoyarse más que en el control social en la organización social. Las circunstancias adversas propiciaron la multiplicación de iniciativas que buscan atacar los motivos que dificultan un aislamiento efectivo: redes de cuidado de personas, organización de compras colectivas, radios comunitarias, cadenas de retroalimentación cultural, iniciativas de creatividad y formación, etc. Algunas de estas acciones ya se producían de manera subrepticia, como militancias y acciones colectivas de subsistencia, pero pocas veces se visibilizan como modelos para seguir, ampliar e institucionalizar. El hecho de que algunos sectores académicos y militantes hayan rescatado estas prácticas no ha logrado instalarlas en el debate público. Por el contrario, la organización social se encuentra relegada detrás de otras formas de expresión política sobre el espacio público con mayor difusión desde los medios de comunicación, como los aplausos desde los balcones, los cacerolazos, la exposición de banderas y mensajes de apoyo en los frentes de las casas. Son acciones que siguen la misma lógica de expresión política de las redes sociales: el like, el dislike, el retweet y el trolleo, sin llegar a incidir en la auténtica articulación política. Es decir, una expresión política que no implica un compromiso social activo.

Evidentemente, las organizaciones sociales atraviesan procesos largos cuya complejidad excede el recorte arquitectónico-urbanístico. No obstante, la perspectiva disciplinar permite rescatar una enseñanza de experiencias previas: solo las organizaciones sociales que comienzan a actuar en el plano político (disputando el rol del Estado) logran transformaciones urbanas de gran escala ${ }^{19}$.

\section{Recambio tecnológico}

Las intervenciones higienistas de fines del siglo XIX y principios del XX permitieron incorporar una serie de adelantos tecnológicos en la vivienda y la ciudad que transformaron la calidad de vida de una parte de la población del mundo. La ciudad implementó nuevos sistemas de saneamiento, iluminación, transporte y espacios verdes. La vivienda incorporó tanto infraestructuras como materiales asociados al progreso científico y la Revolución Industrial. El invento del sifón, por ejemplo, desarticuló dos espacios que anteriormente eran de uso colectivo: baño y cocina. Estos espacios claves del imaginario higienista se incorporaron al ámbito más íntimo de la vida familiar, y reforzaron la idea de una unidad habitacional individual por
19. Como antecedentes se podrían mencionar las barriadas de Perú durante la década del 60 (GYGER, 2013), las cooperativas de vivienda en Uruguay (DEL CASTILLO \& VALLÉs, 2015) y la experiencia del MOI (MOVIMIENTO DE OCUPANTES E INQUILINOS) en CABA (ZAPATA, 2017). 
20. Engels destacaba que esta intención de transformar "al proletario en propietario" pretendía disimular las condiciones de sujeción del trabajador con respecto al capital (MARX \& ENGELS, 1975). En Argentina, la posibilidad de acceder a un terreno propio, de reducidas dimensiones, desprovisto de infraestructuras y en

las afueras de la ciudad contribuía a la radicación de los inmigrantes. cada núcleo familiar. Este cambio tipológico reflejaba una normalización del comportamiento popular, según la cual cada individuo quedaba incorporado en un núcleo familiar, confinado en una vivienda compacta, con una vida saludable y alejado de los malos hábitos de la convivencia en colectividad. Pese a ser cambios tecnológicos, motivaron transformaciones sociales que consolidaron el imaginario de la casa propia y la propiedad privada ${ }^{20}$.

En Argentina, esta incorporación tecnológica, que comenzó con las intervenciones higienistas, nunca alcanzó la universalidad, sino que se desarrolló de manera despareja en el territorio nacional. Desde aquel entonces, la irregular distribución de servicios combinada con una concepción liberal de la propiedad de la tierra configuró una matriz de desigualdad territorial y urbana. La relación dialéctica entre infraestructuras y precio del suelo fomenta la concentración de servicios donde habitan las clases de mayores ingresos. Por el contrario, se dejan sin servicios básicos aquellas zonas donde por la misma dinámica del precio del suelo y los alquileres terminan expulsados los grupos de menores ingresos.

Ante la emergencia de la Covid-19, se vuelve a percibir un nuevo optimismo tecnológico que avanza en similar dirección a la modernización guiada por el higienismo. Una modernización que aumenta las desigualdades e introduce reformas sociales sobre la base de justificativos técnicos. La nueva modernización en tiempos de pandemia está marcada por el protagonismo de las tecnologías de la informática y la comunicación (TIC) como herramienta que habilita a la población a llevar una vida plena, pese al distanciamiento social que exige la cuarentena. No es interés de este artículo cuestionar la utilidad cotidiana de las TIC. Interesa destacar que la contingencia de la Covid-19 ha llevado a la incorporación y exaltación de estas tecnologías en actividades donde su aplicación requeriría ciertas consideraciones previas. La consagración de las plataformas virtuales como el ámbito ideal donde organizar la educación y el trabajo revelan aspectos problemáticos.

Al igual que en las épocas marcadas por el higienismo, la incorporación de las tecnologías del momento ha sido irregular y heterogénea. Si a principios del siglo XX las infraestructuras se concentraron en las áreas pobladas por los sectores de mayor nivel adquisitivo, esto mismo sucedió con las telecomunicaciones a principios del siglo XXI. Pensar que toda la población puede utilizar las TIC, en reemplazo del ámbito público, constituye un error o una vocación excluyente.

La acelerada incorporación de plataformas digitales en el ámbito de la educación responde, más que a una estrategia integral, a una reacción improvisada. En esta iniciativa cabe 
rescatar la noble intención de mantener el contacto entre docentes y alumnos como una manera de propiciar la coordinación de actividades sencillas y la contención en tiempos de ansiedad colectiva. Sin embargo, existe el peligro de concebir el cursado virtual como un natural reemplazo de la modalidad presencial. Por un lado, la implementación del cursado virtual consolida las desigualdades entre quienes cuentan con buena provisión y manejo de telecomunicaciones y quienes carecen de ellas. Por otro lado, esta modalidad termina desdibujando algunos acuerdos básicos con respecto al sistema educativo, dentro de los cuales habría que destacar el valor positivo de una formación en ámbitos de interactuación colectiva y la idea de que el aprendizaje implica un proceso complejo (CAPorossi, 2020), difícil de emular en la linealidad programada de las plataformas informáticas.

En el ámbito laboral, el teletrabajo se concibe como una nueva modalidad que llegó para quedarse. Si bien hay que destacar algunos beneficios, como la reducción del impacto ambiental por el transporte, la poca predisposición a discutir sus desventajas despierta sospechas con respecto a las intenciones que sustentan estos cambios ${ }^{21}$. En primer lugar, el teletrabajo vuelve a evidenciar la brecha digital ${ }^{22}$. Las grandes empresas que vienen apostando por el uso de las TIC para mediar los procesos de producción, gestión y consumo tienen una amplia ventaja frente a los sectores informales o emprendimientos de pequeña y mediana escala (como empresas familiares) con poca capacidad de inserción a través de Internet.

Con respecto al poder que tienen algunas tecnologías para disciplinar a la población, es importante notar que el teletrabajo permite llevar la producción a un ámbito totalmente desregulado, como es el seno del hogar. Un lugar sin horarios ni reglamentaciones, que permite organizar toda la vida íntima del empleado en función del objetivo de máxima productividad. Se pierden así las mínimas protecciones que brindaba el ámbito colectivo, transformándose en una relación de respuesta constante, individual, filtrada de cualquier tipo de apoyo colectivo o disputa gremial.

Las exigencias de la pandemia aceleran un cambio tipológico en la vivienda ya anunciado por Paul Preciado y Beatriz Colomina. La provisión de infraestructuras de telecomunicaciones convierte el dormitorio en un ámbito laboral, donde el trabajador se transforma según la lógica del emprendedor free-lance conectado las veinticuatro horas del día ${ }^{23}$. Por un lado, el teletrabajo permite disolver el límite entre trabajo y ocio (Preciado, 2020). Por otro lado, la hiperconectividad llevada a los espacios más íntimos permite también una producción inconsciente de datos e información sobre nuestras necesidades, temores y gustos más
21. Las restricciones aplicadas al uso del espacio público y el transporte no tienen un impacto homogéneo en la población, y afectan principalmente al sector dependiente de la economía informal. Es decir, a una población mayoritaria en Latinoamérica, cuya subsistencia diaria depende de su presencia física en un lugar determinado. De acuerdo con la CEPAL (Comisión Económica para América Latina y el Caribe), en 2016 el 53,1\% de los trabajadores de América Latina y el Caribe trabajaba en el sector informal (CEPAL, 2020).

22. Un informe de CIPPEC (Centro de Implementación de Políticas Públicas para la Equidad y el Crecimiento), revela que la Encuesta de Indicadores Laborales (EIL) de 2017 muestra que solo un $3 \%$ de las empresas implementan teletrabajo. Este informe advierte que el porcentaje de trabajos que pueden realizarse desde el hogar es de un $27 \%$ a un 29 $\%$ del total de trabajos. Este dato que es "potencial", no tiene cuenta la brecha digital, sino refleja las tareas que son posibles de desarrollar de forma remota (ALBRIEU, 2020). 
23. "La industrialización trajo la jornada laboral de 8 horas y una separación radical entre el hogar y la oficinal

fábrica, el descanso y el trabajo, la noche y el día. La post-industrialización volvió a llevar el trabajo dentro del

hogar, y fue aún más lejos, lo llevo dentro al dormitorio e incluso a la cama". Traducción propia (CoLominA, 2014, p. 19).

24. "Por egoísmo, las gentes acomodadas de las poblaciones deben cuidar del modo de vivir de los pobres, porque la salubridad de una ciudad es un resultado de muchos factores y no un producto de la acción individual o colectiva aplicada a una sola sección, a una calle, a un barrio" (DR. EDUARDO WILDE citado en CRAVINO, 2016, p. 10). profundos (Colomina, 2014). Esta constante producción de datos individualizados alcanza hoy un valor extraordinario para consultoras empresariales y políticas.

Del mismo modo que la vivienda propia, individual y compacta, provista de infraestructura sanitaria sirvió como un dispositivo para disciplinar a la población según los requisitos del capitalismo industrial, la provisión de infraestructura de telecomunicaciones alrededor del dormitorio surge como una adecuación tipológica para este nuevo capitalismo post-coronavirus. En ese camino, avanza la exaltación en la prensa especializada y la proliferación en el mercado de algunas tipologías que enaltecen valores como la autonomía, la flexibilidad y el aire bucólico de la soledad, como los lofts, las tiny houses o los monoambientes. Lejos de todo romanticismo, detrás de estas tipologías se constata — cuando no es una simple reducción de metros cuadrados por razones presupuestarias - un elevado nivel de atomización de la sociedad.

\section{Intervenciones habitacionales}

Las ideas higienistas del siglo XIX sirvieron de sustento a las primeras iniciativas filantrópicas que buscaron mejorar las condiciones de vida de la población de menores ingresos. Estas primeras líneas de acción abrieron el camino a sectores reformistas vinculados con la Iglesia católica, asociaciones sindicales y, poco después - ante la amenaza de posibles levantamientos populares-, con el Estado. Incluso en la defensa de sus propios intereses, las elites comprendieron que era necesario intervenir en el mejoramiento de las condiciones habitacionales de los sectores populares. Entendían que estas condiciones de miseria podían poner en riesgo la salud y el equilibrio de toda la sociedad ${ }^{24}$.

En tiempos de la Covid-19, resulta imperioso recuperar la responsabilidad colectiva sobre las condiciones de vida en la ciudad. No se trata de rescatar una visión tecnocrática que buscaba depositar en manos de especialistas de la higiene la complejidad de la vida urbana. Tampoco interesa retomar el sentido caritativo de la filantropía. Lo que se propone destacar es que el higienismo logró instalar una visión sistémica, en la cual las condiciones deficitarias no dependían únicamente del esfuerzo propio, sino que exigían, además, enérgicas acciones colectivas.

La cuarentena que intenta limitar la propagación de la Covid-19 ha vuelto a traer a la discusión la alarmante desigualdad en las condiciones habitacionales de la población urbana. En 
grandes porciones de la ciudad latinoamericana, la permanencia obligatoria en la residencia implica una serie de peligros poco difundidos desde la prensa pero siempre latentes en la vida cotidiana de la población. Las viviendas deficitarias son una puerta abierta a otras pandemias, como el dengue ${ }^{25}$; presentan poca 0 nula protección ante las inclemencias climáticas; el hacinamiento y las precarias condiciones sanitarias pueden generar focos de infecciones y, combinadas con otras problemáticas sociales, potencian situaciones de violencia de género ${ }^{26}$.

A partir de la contingencia de esta pandemia, interesa rescatar el rol del Estado como garante del acceso universal a condiciones habitacionales dignas, mediante la combinación de políticas públicas integrales. En Argentina, a pesar de la importante intervención estatal en materia habitacional a lo largo de la historia, nunca se logró incidir en la escala y complejidad de la problemática ${ }^{27}$. De acuerdo con BARRETo, en nuestro país "la política habitacional se encuentra atravesada por una tensión entre las concepciones de la vivienda social como derecho social y como bien de acceso por el mercado” (BARRETO, 2018, p. 401).

Frente a la crisis causada por la Covid-19, el gobierno nacional congeló el precio de los alquileres y suspendió los desalojos hasta el mes de septiembre ${ }^{28}$. Esta medida, que hubiera parecido utópica antes de la pandemia, evidencia que el Estado cuenta con diversos instrumentos para incidir en la problemática habitacional, más allá de la siempre necesaria construcción de viviendas nuevas.

Un abordaje integral del hábitat implica, además de construir viviendas y subsidiar créditos hipotecarios, avanzar en la planificación territorial aplicando una perspectiva social sobre la regulación del suelo y el mercado inmobiliario. Es un momento oportuno para implementar una serie de estrategias ampliamente estudiadas por investigadores del ámbito local e internacional, acciones incorporadas, también, en agendas internacionales.

Estas reflexiones no pretenden constituirse en el típico sermón profesional de quien se apoya en la fraseología disciplinar para recomendar transformaciones abstractas de la sociedad. Por el contrario, la pandemia de la Covid-19 exige un reposicionamiento de las disciplinas proyectuales. Es una oportunidad para recuperar aquellas búsquedas que cuestionan el excesivo formalismo
25. Respecto del dengue, "en 2019 se infectaron más de 3 millones de personas (la mayor cifra registrada en la historia de la región) y 1.538 personas murieron a causa de la enfermedad" (CEPAL, 2020, p. 10). "En Argentina, en la presente temporada [...] se notificaron al Sistema Nacional de Vigilancia de la Salud 39.573 casos con sospecha de dengue u otros arbovirus [...] de los cuales 14.237 resultaron confirmados" (DIRECCIÓN NACIONAL DE EPIDEMIOLOGÍA Y ANÁLISIS DE LA SITUACIÓN DE SALUD, 2020).

26. "Hasta el 20 de marzo se registró un femicidio cada 32 horas en Argentina [...] Solamente en marzo hubo 4533 llamadas a la Línea 144 desde la Ciudad de Buenos Aires (casi 200 pedidos más que en marzo del año pasado)" (PEKER, 2020).

27. "En Argentina, desde hace varias décadas, el déficit habitacional sólo ha mejorado en términos relativos [...] pero en términos absolutos se ha mantenido bastante estable en torno a los tres millones de viviendas." (BARRETO, 2018, p. 405).

28. Los elementos más importantes del decreto 320/2020 son: el art. 2 suspende los desalojos por falta de pago. El art. 3 prorroga la vigencia de los contratos. El art. 4 congela los precios de los alquileres. El art. 8 obliga al locador a brindar sus datos bancarios para realizar los pagos por transferencias. El art. 10 establece la excepción en caso de vulnerabilidad del locador. (BOLETIN OfICIAL DE LA REPÚBLICA ARGENTINA, 2020). 
superficial de la Arquitectura y el Urbanismo, y debatir su corresponsabilidad en la dinámica de la especulación urbana.

\section{Conclusiones}

Este trabajo realiza un paralelismo entre las intervenciones guiadas por la cosmovisión higienista del siglo XIX y los desafíos que emergen ante la pandemia de la Covid-19. Para realizar esta comparación se recuperan tres aspectos centrales en el higienismo: el control social, la innovación tecnológica y la responsabilidad colectiva sobre el mejoramiento de las condiciones del hábitat. Al repasar estos tres aspectos se puede extraer una serie de reflexiones que, si bien no pueden considerarse concluyentes por referirse a fenómenos en desarrollo, buscan alcanzar una postura profesional crítica y propositiva en lo que se percibe como un momento clave para el devenir de la ciudad.

Con respecto a la normatividad social, la expansión de la Covid-19 requirió la implementación de una serie de medidas universales que transformaron repentinamente la vida en las ciudades. Estas medidas, que pueden sintetizarse como estrategias de restricción y vigilancia, se transformaron en herramientas poderosas para combatir la expansión del virus. Sin embargo, hay que mencionar que estas medidas fundamentadas en criterios de salud pública contribuyeron a reflotar el espíritu represivo y normalizador de la cosmovisión higienista del siglo XIX. Ante una amenaza generalizada, vuelve a surgir una mirada social condenatoria sobre aquellas personas que, por razones históricamente consolidadas, se ven imposibilitadas de adoptar ciertos comportamientos preestablecidos por motivos de salud pública.

En el siglo XIX las elites veían una amenaza en el modo de vida de la población de menos ingresos. Sin entender del todo las causas estructurales que determinaban la degradación de las condiciones habitacionales de ciertos sectores de la ciudad, las intervenciones apoyadas en criterios higienistas promovieron normativas e incorporaron nuevas infraestructuras para transformar los patrones de comportamiento de la población. Los cambios tecnológicos implementados establecieron un modo de vida moldeado según la mirada higienista. Si bien este patrón civilizatorio se convirtió en un parámetro universal, las innovaciones tecnológicas se distribuyeron de manera muy irregular en el territorio, acentuando las desigualdades entre la población que accedía a estas infraestructuras y la población excluida. 
Esta lectura del contexto de fines del siglo XIX permite establecer un segundo punto de contacto con respecto a la situación generada por la propagación del coronavirus. La confianza que profesaron los higienistas frente a las infraestructuras de saneamiento guarda un paralelismo con respecto a una implementación acrítica y mesiánica de las tecnologías de la informática y las comunicaciones (TIC) como estrategia para contrarrestar y sobrellevar la pandemia. Lejos de cuestionar las ventajas del saneamiento y la utilidad de las TIC, se procura interpelar, en primer lugar, la supuesta universalidad de estas tecnologías. Por depender de infraestructuras irregularmente distribuidas en el territorio y la ciudad, estas tecnologías esconden profundas desigualdades, que pueden acentuarse ante la adopción de medidas apresuradas. En segundo lugar, interesa debatir con respecto a los modos de vida que impone la adopción acrítica de estas tecnologías, alertando sobre algunos intereses velados en su rápida implementación en algunos campos estratégicos como la educación y el trabajo.

El último punto de comparación está centrado en la responsabilidad colectiva sobre las condiciones habitacionales. Este apartado incluye una crítica con respecto a la visión paternalista del higienismo, pero rescata la intención de volver a situar el mejoramiento del hábitat como una prioridad colectiva, que debe ser asumida con el protagonismo de las instituciones públicas. La contingencia de la Covid-19 evidencia las profundas desigualdades urbanas, donde la adopción de medidas universales, como la cuarentena o el lavado de manos frecuente, resulta imposible para una parte de la población. Esta desigualdad evidente vuelve a posicionar las problemáticas habitacionales en el centro del debate público.

Tampoco se trata de emular los fundamentos que sustentaban las intervenciones del siglo XIX. Mientras estas transformaciones higienistas se apoyaban en criterios paternalistas y de salvaguarda del orden preestablecido, se propone fundar las futuras intervenciones del Estado en el ejercicio de derechos. Promover un nuevo involucramiento colectivo que apunte a salir de esta crisis siguiendo el aporte de las recientes investigaciones en materia habitacional. Esta salida deberá complementar la necesaria construcción de viviendas y provisión de infraestructuras iniciada a fines del siglo XIX con políticas integrales que abarquen la planificación territorial, la regulación del mercado del suelo y los alquileres, para garantizar el acceso universal a condiciones habitacionales dignas. 


\section{Referencias bibliográficas}

ALBRIEU, Ramiro (2020). Evaluando las oportunidades y los límites del teletrabajo en Argentina en tiempos del Covid-19. Buenos Aires: CIPPEC.

AVERSA, María Marta y NOVOA FARKAS, Marianela Soledad (2015). Reglamentos de construcción, Casas de Renta y Cines-Teatros. Congreso de Historia de los Pueblos de la Provincia de Buenos Aires. XV, págs. 1-13. La Plata: CIC Digital.

BARRETO, Miguel Ángel (2018). La política habitacional de Cambiemos: el retorno de la mercantilización de la vivienda social en Argentina. Estudios Demográficos y Urbanos, 33, 401-436.

BENEVOLO, Leonardo (1963). Historia de la Arquitectura Moderna. Madrid: Taurus ediciones.

BOIXADÓS, María Cristina (2012). La vivienda como parte de las políticas de salud del municipio del municipio de Córdoba a fines del siglo XIX y principios del XX. Universidad Nacional de Córdoba.

BOLETÍN OFICIAL DE LA REPÚBLICA ARGENTINA (11 de abril de 2020). Aislamiento social preventivo y obligatorio DNU 355/2020. Recuperado de https://www. boletinoficial.gob.ar/detalleAviso/primera/227694/20200411

BOLETÍN OFICIAL DE LA REPÚBLICA ARGENTINA (29 de marzo de 2020). Emergencia Pública. Decreto 320/2020. Recuperado de https://www.boletinoficial.gob. ar/detalleAviso/primera/227247/20200329

BURGESS, Rod (1978). Petty Commodity Housing or Dweller Control? A Critique of John Turner's Views on Housing Policy. World Development, 6, 1105-1133.

CAPOROSSI, Celina (2020). La enseñanza en época de pandemia. Café de las Ciudades. Recuperado de https://cafedelasciudades.com.ar/sitio/contenidos/ver/311/ la-ensenanza-en-epoca-de-pandemia.html?fbclid=IwAR0lTX_SUvnfTdA9292VPUnBvFwpf2q7gYppEOHj_zkQjF7kNTGz7zWToJU

CEPAL (2020). Informe Especial Covid-19 No 1. América Latina y el Caribe ante la pandemia del Covid-19. Efectos económicos y sociales. Naciones Unidas.

COLOMINA, Beatríz (2014). The century of the bed. Viena: Verlag fur Moderne Kunst.

CRAVINO, Ana (2016). Historia de la vivienda social. Primera Parte: el conventillo a las casas baratas. Vivienda y Ciudad, 3, 7-24.

DEL CASTILLO, Alina y VALLÉS, Raúl (2015). Cooperativas de Vivienda en Uruguay. Medio siglo de experiencias. Montevideo: Facultad de Arquitectura. Universidad de la República. 


\section{DIRECCIÓN NACIONAL DE EPIDEMIOLOGÍA Y ANÁLISIS DE LA SITUACIÓN DE}

SALUD (2020). Boletín integrado de vigilancia. Edición semanal. N. ${ }^{\circ}$ 492 SE14/2020. Ministerio de Salud Argentina.

GARCÍA VÁZQUEZ, Carlos (2016). Teorías e Historia de la Ciudad Contemporánea. Barcelona: Gustavo Gili SL.

GYGER, Helen Elizabeth (2013). The Informal as a Project: Self-Help Housing in Peru, 19541986. Nueva York: Columbia University.

HALL, Peter (1996). Ciudades del mañana. Historia del urbanismo de siglo XX. Barcelona: Ediciones del Serbal.

HAN, Byung-Chul (22 de marzo de 2020). La emergencia viral y el mundo de mañana. $E l$ país. Recuperado de https://elpais.com/ideas/2020-03-21/la-emergenciaviral-y-el-mundo-de-manana-byung-chul-han-el-filosofo-surcoreano-quepiensa-desde-berlin.html

KLEIN, Naomi (2010). La doctrina del shock. El auge del capitalismo del desastre. Barcelona: Paidós.

LA TINTA (7 de abril de 2020). Informe sobre la cuarentena en los barrios populares: segunda parte. Recuperado de https://latinta.com.ar/2020/04/informe-cuarentena-barrios-populares-2/

MARKUS, Gabriel (24 de marzo de 2020). El orden mundial previo al virus era letal. El País. Recuperado de https://elpais.com/cultura/2020/03/21/ babelia/1584809233_534841.html

MARX, Karl y ENGELS, Friedrich (1975). Obras Escogidas. Madrid: Akal.

MEDINA DE LA GARZA, Carlos y KOSCHWITZ, Martina Christine (2011). Johann Peter Frank y la medicina social. Medicina Universitaria, 13(52), 163-168.

MINISTERIO DE DESARROLLO TERRITORIAL Y HÁBITAT (17 de abril de 2020). Registro nacional de barrios populares. Recuperado de: https://www.argentina. gob.ar/renabap

MINISTERIO PÚBLICO DE LA DEFENSA CABA (2020). Informe MPD CABA asistencias penales y violencia institucional. Ciudad Autónoma de Buenos Aires: Dirección de Asistencia a las Personas Privadas de la Libertad y el Programa contra la Violencia Institucional del MPD. Recuperado de https://www.mpdefensa.gob.ar/comunicacion/mas-noticias/informe-delmpd-violencia-institucional-durante-la-cuarentena

OYON BAÑALES, José Luis (2003). Historia urbana e historia obrera: reflexiones sobre la vida obrera y su inscripción en el espacio urbano, 1900-1950. Perspectivas Urbanas/Urban Perpectives, 1-28. 
PAIVA, Verónica (1997). Higienismo: ciencia, instituciones y normativa. Buenos Aires, siglo XIX. Seminario de Crítica (págs. 1-34). Instituto de Arte Americano e Investigaciones Estéticas.

PEKER, Luciana (18 de abril de 2020). Femicidios en cuarentena: piden que se declare la emergencia en violencia de género. Infobae. Recuperado de: https://www. infobae.com/sociedad/2020/04/18/femicidios-en-cuarentena-piden-quese-declare-la-emergencia-en-violencia-de-genero/

PRECIADO, Paul (28 de marzo de 2020). Aprendiendo del virus. El País. Recuperado de https://elpais.com/elpais/2020/03/27/opinion/1585316952_026489.html

RIBEIRO, Silvia (03 de abril de 2020). No le echen la culpa al murciélago. (C. Korol, entrevistador). Página 12. Recuperado de: https://www.pagina12.com. ar/256569-no-le-echen-la-culpa-al-murcielago

RODULFO, María Beatríz y BOSELLI, Teresa (2015). ¿Quo vadis FONAVI? Una perspectiva de la política habitacional Argentina. En M. Á. Barreto y M. Lentini, Hacia una política integral del hábitat. Aportes para un observatorio de política habitacional en Argentina (págs. 247-312). Ciudad Autónoma de Buenos Aires: Café de las Ciudades.

TN, TODO NOTICIAS (20 de marzo de 2020). Cuarentena | Prohíben la circulación dentro de countries y barrios cerrados de Pilar. Recuperado de https://tn.com. ar/sociedad/cuarentena-prohiben-la-circulacion-dentro-de-countries-ybarrios-cerrados-de-pilar_1046321

YUJNOVSKY, Oscar (1974). Políticas de vivienda en la ciudad de Buenos Aires (1880-1914). Desarrollo Económico, 14(54), 327-372.

ZAPATA, María Cecilia (2017). La política habitacional porteña bajo la lupa. De los programas llave en mano a la autogestión del hábitat. (T. Mathov, Ed.) Ciudad Autónoma de Buenos Aires: Teseo. 